\title{
Alkane sorption in molecular sieves: The contribution of ordering, intermolecular interactions, and sorption on Brønsted acid sites
}

\author{
Florian Eder and Johannes A. Lercher \\ University of Twente, Department of Chemical Technology, Enschede, The Netherlands
}

\begin{abstract}
Distinct molecular ordering of sorbed alkanes is observed in MFI zeolites when the chain length of the alkane is similar to the length of the zig-zag channels (i.e., with $n$-hexane and $n$-heptane). In contrast, sorbate-sorbate interactions lead to an increase of the heat of adsorption with increasing loading in large pore molecular sieves such as faujasites. The maximum heat released through these interactions is $80 \%$ of the heat of condensation of the substance adsorbed. At most three molecules are involved in such intermolecular interactions. A modified Langmuir model is presented that accounts for these sorbate-sorbate interactions. Subtle structural differences are concluded to be of minor importance as, e.g., the different pore structures of H-FAU and H-EMT hardly affected the alkane sorption. The contribution of the direct interaction between the alkane and the acid sites to the heat of adsorption is $10 \mathrm{~kJ} / \mathrm{mol}$ for MFI and $6 \mathrm{~kJ} / \mathrm{mol}$ for FAU. As for acidic zeolites, a compensation effect between entropy and enthalpy of sorption exists for the purely siliceous samples. (c) Elsevier Science Inc. 1997
\end{abstract}

Keywords: MFI; FAU; EMT; microcalorimetry; ordering; isotherm; acid site

\section{INTRODUCTION}

The heat evolving due to the sorption of alkanes in acidic zeolites is the result of different interactions between the sorbate and the pores of the microporous sorbent. The sorbed molecules interact with (i) the zeolite lattice (i.e., the pore walls), (ii) the acid sites, and (iii) with other sorbed molecules. It was reported previously $^{1}$ that the interaction of the alkanes with the zeolite lattice represents the major contribution to the heat of sorption in acidic zeolites. However, the data did not allow for a quantitative description of the individual contributions.

To gain quantitative information as to how the interaction between the alkanes and the acid sites contributes to the heat of sorption, neutral and acidic samples of the same structure have to be compared. However, purely siliceous samples are only available for a small number of structures. The most common zeolite in this respect and, thus, the best characterized, is silicalite, i.e., purely siliceous MFI. Several studies addressed the energetics of alkane sorption in this material, determining the heat of adsorption by means of calorimetry ${ }^{2-4}$ and by gravimetry using isosters..$^{5-7}$ The well-established structural parameters of MFI also allow computer simulations of the alkane sorption using energy minimiza-

Address reprint requests to $\mathrm{Dr}$. Lercher at $\mathrm{CT} / \mathrm{ACME}$. University of Twente, P.O. Box 217, 7500 AE Enschede, Netherlands.

Received 3 July 1996; accepted 12 September 1996 tion techniques, ${ }^{8}$ molecular dynamics studies $^{9}$ and Monte Carlo simulations. ${ }^{10-12}$ With FAU and MOR some experimental data of alkane sorption was reported previously for highly dealuminated samples. ${ }^{13,14}$

In addition to the effect of the localized bonding of the alkane, two other effects can influence the thermodynamics of sorption, i.e., intermolecular interactions of the sorbed molecules and well-defined arrangements of the sorbed molecules. The first of the two is conceptually well seen in sorption in large-pore molecular sieves, and indeed such interactions have been reported on $\mathrm{AlPO}_{4}-5$, VPI-5 and faujasite-derived materials. ${ }^{13,14}$ The effect of packing on the other side has only recently drawn attention as a result of being predicted by theoretical calculations and also partly being experimentally confirmed. ${ }^{11,15}$

We report here gravimetric, calorimetric, and i.r. spectroscopic evidence for these phenomena, using molecular sieves of the MFI and FAU structure as model compounds. The data give a clear quantitative picture of the sorptive properties that should allow extrapolation to other less available molecular sieve structure types.

\section{EXPERIMENTAL}

\section{Materials}

Silicalite was provided by the Technical University of Eindhoven, Department for Inorganic Chemistry and 
Catalysis. The typical coffin-shaped crystals had a size of about $50 \times 20 \times 20 \mu \mathrm{m}$. $\mathrm{H}-\mathrm{EMT}\left(\mathrm{Si} / \mathrm{Al}=3.8, \mathrm{H}^{+}\right.$conc. $=$ $3.2 \mathrm{mmol} / \mathrm{g}$ ) was obtained from Fcole Nationale Superieur de Chimie de Mulhouse, Laboratoire de Materiaux Mineraux, as platelets of 1 to $1.5 \mu \mathrm{m}$ diameter and with a thickness of about 0.2 to $0.3 \mu \mathrm{m}$. The high siliceous FAU sample $(\mathrm{Si} / \mathrm{Al}=300$ ) was supplied by TOSOH Corp. This sample consisted of small blocks and cubes with a size of 0.3 to $0.4 \mu \mathrm{m}$. All three samples showed high cristallinity. Propane, $n$-, and iso-butane (purity $>99.5 \%$ ) were obtained from Messer Griesheim Corp., $n$-hexane, $n$ - and iso-pentane (purity >99.5\%) were obtained from Fluka Chemie AG, n-octane, nnonane, and 2-methyl-heptane (purity >99\%) were obtained from Merck, and $n$-heptane was obtained from Sigma-Aldrich.

\section{Gravimetry and calorimetry}

Measurements were performed with a modified SETARAM TG-DSC 111 instrument. Approximately 15 mg of the $\mathrm{NH}_{4}{ }^{+}$-form of EMT was charged into the quartz sample holder of the balance and transferred into the hydrogen form by heating in vacuum $\left(p<10^{-6}\right.$ mbar) with a temperature increment of $10 \mathrm{~K} / \mathrm{min}$ to $623 \mathrm{~K}$ and holding that temperature for $1 \mathrm{~h}$. Silicalite and the high siliceous FAU sample were heated in vacuum with a temperature increment of $10 \mathrm{~K} / \mathrm{min}$ to $773 \mathrm{~K}$ in case of silicalite and to $673 \mathrm{~K}$ in the case of high siliceous FAU, respectively, and held at this temperature for $1 \mathrm{~h}$ to remove water and traces of other substances. Due to the higher thermal stability of silicalite this medium-pore sample was activated at higher temperatures to accelerate the desorption of impurities. This has been shown to produce the same result as activation at the low temperature for the large-pore samples, but occurs over several hours. The sorption experiments were carried out at $323 \mathrm{~K}$ in the case of H-EMT and high siliceous FAU, whereas n-octane on high siliceous FAU was adsorbed at $348 \mathrm{~K}$. The adsorption of $n$-octane, $n$-nonane, and 2-methyl-heptane on silicalite was investigated at $373 \mathrm{~K}$. The adsorption of $n$-hexane was performed at $333 \mathrm{~K}$. Different adsorption temperatures were chosen to meet two contrary requirements, i.e., (i) to prevent chemical reactions of the alkanes (especially with the acidic sample) and (ii) to accelerate the equilibration with the sorbent to obtain integrateable heat signals (especially with the medium-pore silicalite and with longer chain alkanes). The alkanes were discontinuously dosed into the closed system and equilibrated with the surface while the sample weight and the heat flow were recorded. The heat flow measured after the admission of a differential amount of hydrocarbon to the sample was integrated over time, correlated to the mass uptake, and divided by a calibration factor resulting in the differential sorption enthalpy. The temperature-dependent calibration factor was determined at various temperatures by observing phase transitions of inorganic substances. In all cases the measured uptakes were completely reversible. The experiments were carried out in the pressure range from $10^{-3}$ to $13 \mathrm{mbar}$. The pressure was recorded with a BARATRON pressure transducer (type 122A).
The adsorption isotherms of all the hydrocarbons were determined gravimetrically simultaneously with the differential enthalpies of adsorption. The mass uptake at a given partial pressure was corrected for the uptake of the empty system. The concentrations of acid sites were determined gravimetrically by ammonia adsorption/desorption. The equilibrium constants and the directly measured differential enthalpies were used to calculate the Gibbs free energies and the entropies of sorption, respectively.

\section{Infrared spectroscopy}

Spectra were measured with a BRUKER IFS-88 spectrometer in the transmission absorption mode. The EMT sample present in the $\mathrm{NH}_{4}{ }^{+}$form was pressed to self-supporting wafers and was introduced into the heatable sample holder of a vacuum cell. The sample was activated by heating in vacuum $\left(623 \mathrm{~K}, p<10^{-6}\right.$ mbar) for $1 \mathrm{~h}$ and cooled to adsorption temperature. The sorption experiments were carried out at $323 \mathrm{~K}$ and in a pressure range from $10^{-3}$ to 3 mbar. The alkane partial pressure was increased stepwise and after every step equilibration was followed by time-resolved i.r. spectroscopy. The decrease in intensity of the $\mathrm{OH}$ stretching vibrations bands of the Bronstcd acid sites was used to determine the coverage of the acid sites. The integral absorption coefficients of the CHstretching vibrations of the adsorbed alkanes $(2,800-$ $3,000 \mathrm{~cm}^{-1}$ ) were derived by relating the integral intensity to the gravimetric uptake. The integral intensities normalized by the absorption coefficient were used to derive the coverage/pressure dependence of the individual adsorbate species.

\section{RESULTS}

\section{Sorption of alkanes on silicalite}

Figure 1 shows the differential heat of sorption of $n$-heptane on silicalite as a function of the uptake at 373 K. Up to an uptake of about 3.7 molecules per unit cell of silicalite the heat of adsorption was constant. At higher uptake the differential sorption enthalpy decreased sharply. A similar behavior was found for $n$ -

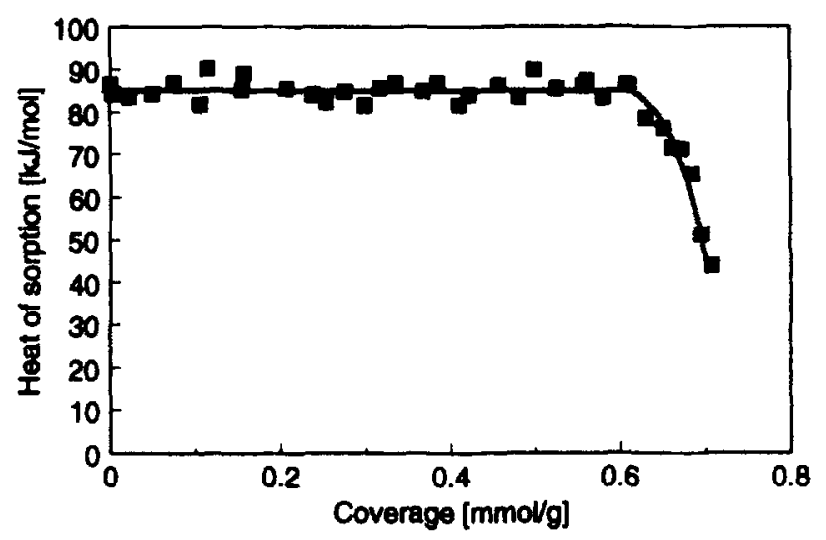

Figure 1 Differential heat of adsorption of $n$-heptane on silicalite as a function of the loading at $373 \mathrm{~K}$. 
octane, $n$-nonane, and 2-methyl-heptane at $373 \mathrm{~K}$, indicating a limited sorption capacity for these longer chain alkanes at $373 \mathrm{~K}$. In contrast, the differential heat of hexane sorption at $333 \mathrm{~K}$ dropped at an uptake value of about 6.5 molecules per unit cell, and a marked decrease in the differential heat of $n$-heptane sorption at $333 \mathrm{~K}$ was not observed up to the maximum loading achieved ( 5.5. molecules per unit cell).

As shown in Figure 2, a kinked shape was found for the sorption isotherms of $n$-hexane and $n$-heptane at $333 \mathrm{~K}$. Although the sorption isotherm of $n$-hexane showed a slight kink at about $50 \%$ of the maximum uptake, the sorption isotherm of $n$-heptane even exhibited a plateau in this uptake regime. The isotherms for $n$-heptane, $n$-octane, $n$-nonane, and 2-methyl-heptane at $373 \mathrm{~K}$ did not show a kinked shape, but the sorption capacity was markedly lower than for $n$-hexane and $n$ heptane.

The differential heat of adsorption increased linearly with the chain length of the adsorbed alkane with an increment of $12 \mathrm{~kJ} / \mathrm{mol}$ from $72 \mathrm{~kJ} / \mathrm{mol}$ for hexane to $107 \mathrm{~kJ} / \mathrm{mol}$ for $n$-nonane. As on H-MFI, the differential heat of adsorption of a single branched iso-alkane was $6 \mathrm{~kJ} / \mathrm{mol}$ lower than the heat value for the corresponding $n$-alkane. The logarithm of the Henry's constants measured or extrapolated to $373 \mathrm{~K}$ exhibited a linear dependence on the carbon number of the alkane sorbed. The values for the differential enthalpy of adsorption, the maximum loading achieved, and the Henry's constants are compiled in Table 1 .

\section{Sorption of alkanes on H-EMT}

The differential heat of hexane sorption on H-EMT as a function of the coverage of $323 \mathrm{~K}$ is represented in Figure 3. As with H-FAU ${ }^{1}$ the differential heat of sorption was constant only at very low coverages. The differential heat of sorption increased with the coverage and suddenly dropped at about 0.6 molcculcs/acid sitc. This indicates that $60 \%$ of the acid sites of the H-EMT sample investigated were located in the supercages. The initial heat of adsorption increased linearly with alkane chain length with an increment of approximately $7 \mathrm{~kJ} / \mathrm{mol} /$ carbon atom and showed nearly the same values as on H-FAL. Also, the uptake curves on

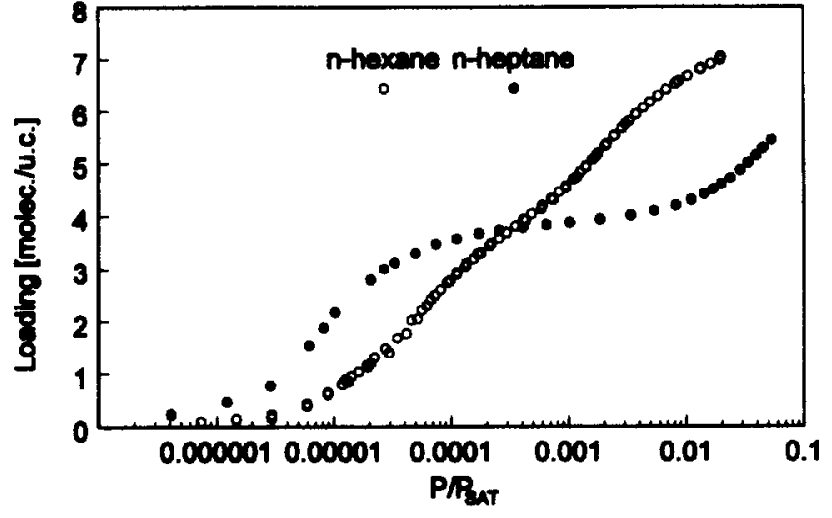

Figure 2 Sorption isotherms of $n$-hexane and $n$-heptane on silicalite at $333 \mathrm{~K}$.

H-FAU and H-EMT were almost identical. The values of the initial enthalpies of sorption, the maximum loading achieved at about 13 mbar, and the Henry's constants are compiled in Table 2.

I.r. spectra of activated H-EMT showed the highfrequency $\mathrm{OH}$ band at $3,635 \mathrm{~cm}^{-1}$ and the lowfrequency band at $3,545 \mathrm{~cm}^{-1}$, respectively. As reported for H-FAU, ${ }^{1}$ the intensity of the HF band decrcased with increasing hydrocarbon partial pressure and disappeared completely at high loadings, indicating that all acid sites located in the supercages of H-EMT interact with alkanes. Due to the interaction between the OH group and the alkane, the HF band was broadened and shifted about $100 \mathrm{~cm}^{-1}$ to lower wave numbers. The LF band was not affected by sorbed alkanes, suggesting that these $\mathrm{OH}$ groups do not interact with alkanes.

\section{Sorption of alkanes on highly siliceous FAU}

Figure 4 shows the differential heat of hexane sorption on FAU as a function of the loading at $323 \mathrm{~K}$. As with $\mathrm{H}$-FAU the differential heat of sorption increased with the loading due to sorbate-sorbate interactions. The values of the initial heat of adsorption increased with the alkane chain length with an increment of approximately $7 \mathrm{~kJ} / \mathrm{mol} /$ carbon atom from $27 \mathrm{~kJ} / \mathrm{mol}$ for propane to $61 \mathrm{~kJ} / \mathrm{mol}$ for $n$-octane. iso-Alkanes exhib-

Table 1 Heat of adsorption, maximum loading achieved at about 13 mbar and Henry's constants (at 373 K) for alkane sorption on silicalite

\begin{tabular}{|c|c|c|c|c|}
\hline & $\underset{(\mathrm{kJ} / \mathrm{mol}\}}{\Delta \mathrm{H}_{\text {ads }}}$ & 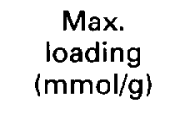 & $\mathrm{P} / \mathrm{P}_{\mathrm{SAT}}$ & $\begin{array}{c}\text { Henry's } \\
\text { constant } \\
\text { (mmol/g*bar) }\end{array}$ \\
\hline $\begin{array}{l}n \text {-hexane } \\
n \text {-heptane } \\
\text { n-cctane } \\
\text { n-nonane } \\
\text { 2-methyl-heptane }\end{array}$ & $\begin{array}{l}-72(-82) \\
-84(-94) \\
-96(-106) \\
-107 \\
-89(-100)\end{array}$ & $\begin{array}{l}1.22^{\mathrm{a}}\left(1.23^{\mathrm{a}}\right) \\
0.73^{\mathrm{b}}\left(1.05^{\mathrm{a}}\right) \\
0.71^{\mathrm{b}}\left(0.71^{\mathrm{b}}\right) \\
0.71^{\mathrm{c}} \\
0.69^{\mathrm{d}}\left(0.71^{\mathrm{b}}\right)\end{array}$ & $\begin{array}{l}1.95^{*} 10^{-2} \\
1.30^{*} 10^{-2} \\
2.79^{*} 10^{-1} \\
9.30^{*} 10^{-3} \\
1.46^{*} 10^{-2}\end{array}$ & $\begin{array}{l}1.4^{*} 10^{3} \\
1.2^{*} 10^{4} \\
9.6^{*} 10^{4} \\
6.1^{*} 10^{5} \\
5.1 * 10^{4}\end{array}$ \\
\hline
\end{tabular}

For comparison the enthalpies and maximum loadings reported for $\mathrm{H}-\mathrm{MFI}^{1}$ are represented in parentheses. The relative pressure of a substance at which the maximum loading was achieved is given in a separate column.

13 mbar and $333 \mathrm{~K}$.

b 12 mbar.

${ }^{c} 2$ mbar.

${ }^{d} 9$ mbar. 
Table 2 Heat of adsorption, maximum loading achieved at about 13 mbar and Henry's constants (at $323 \mathrm{~K}$ ) for alkane sorption on H-EMT

\begin{tabular}{lcccc}
\hline & $\begin{array}{c}\Delta \mathrm{H}_{\text {ads }} \\
\langle\mathrm{kJ} / \mathrm{mol})\end{array}$ & $\begin{array}{c}\text { Max. } \\
\text { loading } \\
(\mathrm{mmol} / \mathrm{g})\end{array}$ & $\mathrm{P} / \mathrm{P}_{\mathrm{SAT}}$ & $\begin{array}{c}\text { Henry's } \\
\text { constant } \\
\left(\mathrm{mmol} / \mathrm{g}^{*} \text { bar }\right)\end{array}$ \\
\hline n-butane & $-39(-39)$ & $1.09(1.31)$ & $2.71 * 10^{-3}$ & $1.3^{*} 10^{2}$ \\
n-pentane & $-47(-46)$ & $2.06(2.14)$ & $9.37^{*} 10^{-3}$ & $8.4^{*} 10^{2}$ \\
n-hexane & $-53(-53)$ & $2.09(2.10)$ & $2.73^{*} 10^{-2}$ & $6.1 * 10^{3}$ \\
iso-pentane & $-47(-46)$ & $1.92(1.98)$ & $6.86 * 10^{-3}$ & $7.4^{*} 10^{2}$ \\
\hline
\end{tabular}

For comparison the values reported for $\mathrm{H}-\mathrm{FAU}^{1}$ are represented in parentheses. The relative pressure of a substance at which the maximum loading was achieved is given in a separate column.

ited a slightly lower heat of sorption than the corresponding n-alkanes. As with H-FAU the Henry's constant increased exponentially with the carbon number of the molecules adsorbed, and the sorption isotherms of alkanes on siliceous FAU showed a strong deviation from an ideal Langmuir shape. The values of the initial enthalpies of sorption, the maximum loading achieved at about 13 mbar, and the Henry's constants are compiled in Table 3.

\section{DISCUSSION}

\section{Ordering of molecules in zeolite pores}

Figure 2 indicates the kinked shape found for the sorption isotherms of $n$-hexane and $n$-heptane on silicalite. Alkanes smaller than $n$-hexane and larger than $n$-heptane had sorption isotherms of type $\mathrm{I}$, whereas the sorption isotherm of $n$-hexane at $333 \mathrm{~K}$ exhibited a marked kink at about $50 \%$ of the maximum uptake. The sorption isotherm of $n$-heptane at $333 \mathrm{~K}$ showed even a distinct plateau at this loading with both samples. This causes higher loadings with $n$-hexane than with $n$-heptane at alkane partial pressures higher than 0.1 mbar.

The behavior agrees well with predictions from Monte Carlo simulations by Smit et al. 'These simulations indicate that the deviation from a type-I isotherm only occurs if the length of the hydrocarbon molecule and the length of the rig-7ag channel of MFI zeolites are similar. At low loadings the molecules can move freely in the zig-zag channels and, thus, also populate the intersections for some time. If a part of the intersections is occupied, the straight channels cannot accommodate other molecules. To fill the zeolite completely, the molecules sorbed in the zig-zag channels have to be confined in their position, leading to an entropy loss that has to be compensated by higher pressure (i.e., chemical potential).

Similarly, one is able to rationalize why such ordering was not observed for molecules longer than $n$-heptane or shorter than $n$-hexane. Longer molecules will always be partly in the intersections and, thus, occupy (parts of) the straight channels under any circumstances. Shorter molecules will leave the straight channels accessible to alkanes without necessarily being confined to the zig-zag channels.

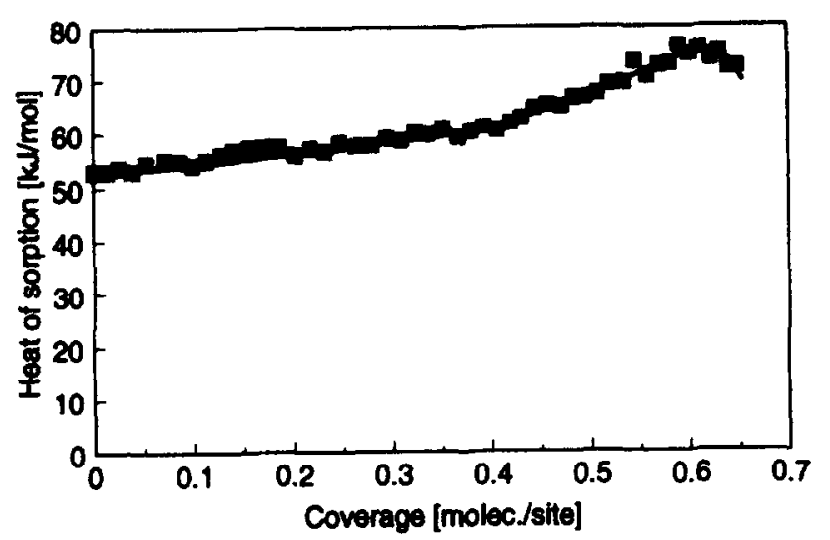

Figure 3 Differential heat of adsorption of n-hexane on H-EMT as a function of the coverage at $323 \mathrm{~K}$.

The kink or plateau is expected to be more pronounced at higher temperatures as the contribution of the cntropy term is more important and higher partial pressures have to be applied to confine $n$-hexane or $n$-heptane to the zig-zag channels. In this respect it is interesting to note that the sorption isotherm of $n$ heptane on silicalite at $373 \mathrm{~K}$ did not exhibit a plateau, but the maximum uptake reached under this conditions corresponded well to the uptake level where a plateau was observed at $333 \mathrm{~K}$. This indicates that the contribution of the entropy at $373 \mathrm{~K}$ is so large that it cannot be compensated by increasing the partial pressure, i.e., the thermal motions of $n$-heptane molecules at $373 \mathrm{~K}$ are so high that the molecules cannot be constrained to the zig-zag channels.

\section{Influence of the pore shape}

These observations and previous results ${ }^{1}$ clearly show that the sorption energetics and the siting of alkanes depend on subtle details of the molecular sieve structure. Thus, one might speculate that subtle differences in the pore structure such as these between FAU and EMT should be reflected in the sorption properties. However, the initial enthalpies of sorption for alkanes were almost identical for $\mathrm{H}$-FAU and $\mathrm{H}$-EMT (see Table

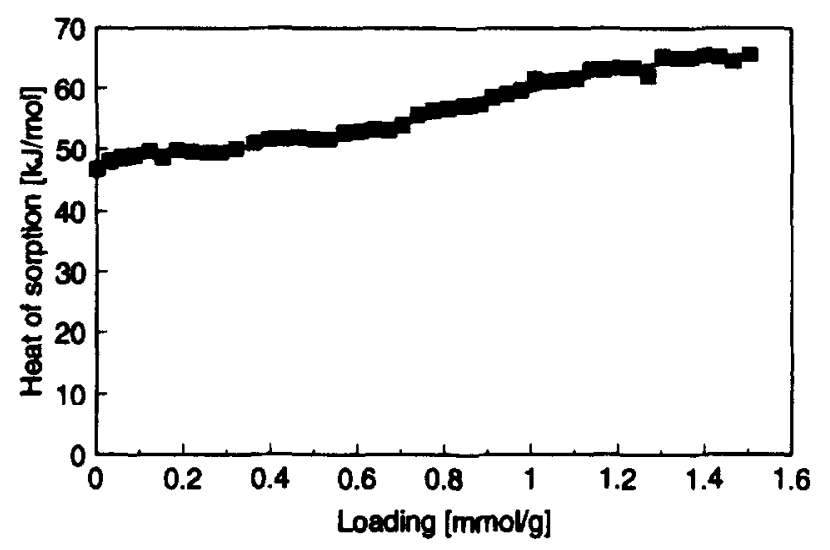

Figure 4 Differential heat of adsorption of $n$-hexane on highly siliceous FAU as a function of the loading at $323 \mathrm{~K}$. 
3). The differential heat of adsorption of a particular alkane increased in the same way with increasing loading on both zeolites. Furthermore, the uptake curves for a given substance on the two zeolites resulted in nearly coincident lines (see Figure 5). This suggests that alkane sorption in acidic FAU and EMT is primarily controlled by the interactions of the alkane molecules with the local environment in the supercages. The different shape and array of these cages seem not to significantly influence the sorption process.

\section{Influence of intermolecular interactions}

The increase in the differential heat of alkane sorption with increasing loading indicates that the supercages of FAU and E.MT are sufficiently large to allow for sorbate-sorbate interactions. Because of the high acid site density of H-FAU and H-EMT, we conclude that molecules adsorbed on neighboring sites can interact with one another. The contribution of such interaction to the heat of adsorption increases with the loading (as the probability that two or more molecules mutually interact increases). Intrinsically, this additional enthalpy must depend on the average number of adsorbed molecules mutually interacting. Thus, the dependence of this enthalpy contribution upon the concentration of alkane adsorbed can be described by Equation (1).

$$
Q_{s-s} \propto n^{x}
$$

$Q_{\text {s-s }}$ is the integral heat evolved due to sorbate-sorbate interactions, $n$ is the amount of alkane adsorbed, and $x$ is the number of molecules mutually interacting. Compiling $Q_{s-s}$ as a function of $n$ in a double logarithmic diagram results in a line with the slope $x$, the value being between 2.5 and 3 for all alkanes. This suggests that molecules sorbed in FAU and EMT can interact with at most two other sorbed molecules. The differential heat of adsorption on H-FAU increased with the loading due to these interactions for a maximum of 21 $\mathrm{kJ} / \mathrm{mol}$ with $n$-pentane, $23 \mathrm{~kJ} / \mathrm{mol}$ with $n$-hexane, and $29 \mathrm{~kJ} / \mathrm{mol}$ with $n$-octane. These values are approximate $80 \%$ of the heat of condensation of these substances

Table 3 Heat of adsorption, maximum loading achieved at about 13 mbar and Henry's constants (at $323 \mathrm{~K}$ ) for alkane sorption on FAU

\begin{tabular}{lcccc}
\hline & $\begin{array}{c}\text { Max. } \\
(\mathrm{kJ} / \mathrm{H} / \mathrm{mol})\end{array}$ & $\begin{array}{c}\text { Menry's } \\
\text { loading } \\
(\mathrm{mmol} / \mathrm{g})\end{array}$ & $\mathrm{P} / \mathrm{P}_{\text {SAT }}$ & $\begin{array}{c}\text { Henry's } \\
\text { constant } \\
\left(\mathrm{mmol} / \mathrm{g}^{*} \text { bar }\right)\end{array}$ \\
\hline propane & -27 & $0.06^{\mathrm{a}}$ & $7.2^{*} 10^{-4}$ & $4.5^{*} 10^{\circ}$ \\
n-butane & -34 & $0.28^{\mathrm{a}}$ & $2.72^{*} 10^{-3}$ & $2.6^{*} 10^{1}$ \\
n-pentane & -41 & $1.32^{\mathrm{a}}$ & $9.38^{*} 10^{-3}$ & $1.2^{*} 10^{2}$ \\
n-hexane & -47 & $1.53^{\mathrm{a}}$ & $2.77^{*} 10^{-2}$ & $6.2^{*} 10^{2}$ \\
n-octane & -61 & $1.14^{\mathrm{b}}$ & $2.36^{*} 10^{-1}$ & $1.6^{*} 10^{4}$ \\
iso-butane & -33 & $0.23^{\mathrm{a}}$ & $2.10^{*} 10^{-3}$ & $2.4^{*} 10^{1}$ \\
iso-pentane & -39 & $1.14^{\mathrm{a}}$ & $6.80^{*} 10^{-3}$ & $1.0^{*} 10^{2}$ \\
\hline
\end{tabular}

The relative pressure of a substance at which the maximum loading was achieved is given in a separate column. a $323 \mathrm{~K}$.

b $348 \mathrm{~K}$ and 4 mbar.

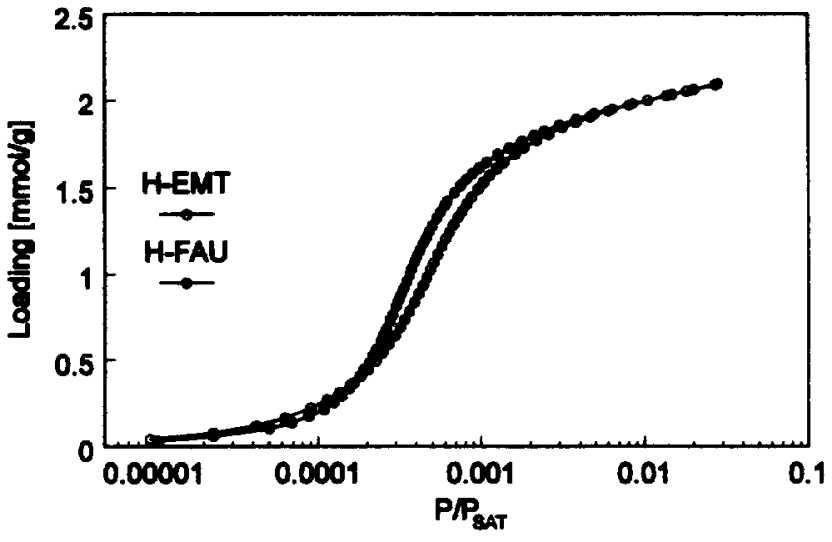

Figure 5 Sorption isotherms of $n$-hexane on H-EMT and H-FAU at $323 \mathrm{~K}$

(25.8, 28.9, and $34.6 \mathrm{~kJ} / \mathrm{mol}$ for $n$-pentane, $n$-hexane, and $n$-octane, respectively).

In addition to the influence on the differential heat of adsorption, sorbate-sorbate interactions also influence the uptake curves. The sorption isotherms on $\mathrm{H}$ FAU, FAU, and H-EMT cannot be fitted to a single or a sum of Langmuir isotherms (see Figure 6). By sorbing alkane molecules, energetically favored sorption sites are created, i.e., sites with neighboring preadsorbed molecules. In contrast to a dissociative adsorption taking place only when two neighboring sorption sites are free, this process is named accumulative sorption. Therefore, the sorption isotherms on FAU and related open structures have to be fitted to a model consisting of two different terms: one Langmuir term describing the sorption on sites without neighboring molecules, i.e., sorption at low loadings, and one term describing the accumulative sorption that determines the uptake curves at higher loadings. As shown above, the molecules sorbed in FAU can interact with at most two other molecules. Therefore, an arrangement of a maximum of three sorption sites is necessary. In reverse analogy to the mathematical description of the dissociative sorption, this leads to a dependence of the loading due to accumulative sorption on the cube of the

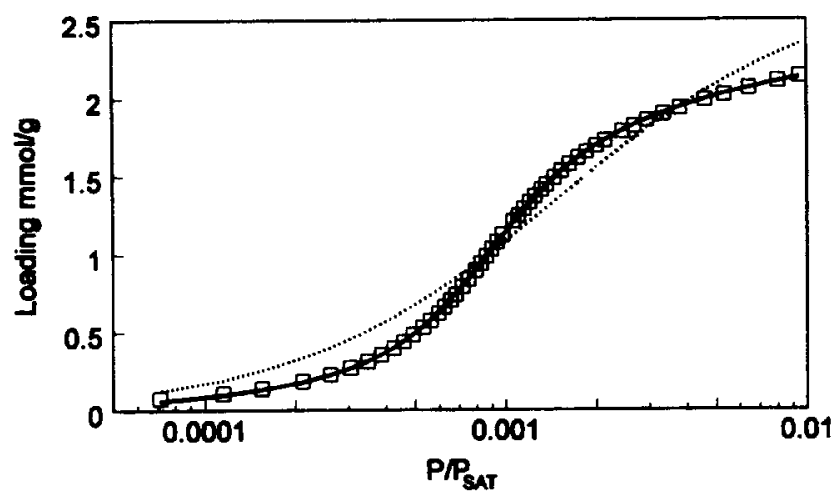

Figure 6 Sorption isotherm of n-pentane on H-FAU at $323 \mathrm{~K}$ : ( $\square$ ) experimental data, (...) fitted according to a Langmuir model and (-) according to Equation (2). 
adsorption constant and the partial pressure. Together with the term for the sorption at low loadings, the following expression is obtained:

$$
\theta=\chi * \frac{k_{1} * p}{\left(1+k_{1} * p\right)}+(1-\chi) * \frac{\left(k_{2} * p\right)^{3}}{\left(1+\left(k_{2} * p\right)^{3}\right)}
$$

$k_{1}$ and $k_{2}$ are the sorption constants for the sorption at low loadings and the accumulative sorption, respectively, and the factor $\chi$ accounts for the distribution between the contributions of these two sorption states. As can be seen in Figure 6, this simple, empirical model describes well the sorption isotherms on FAU and related structures.

\section{Influence of the acid sites}

To determine the contribution of the acid sites to the heat of adsorption, the sorption enthalpy on purely siliceous and acidic samples of the same structure were compared. As shown in Figure 7, the initial heat of adsorption on the acidic samples and the siliceous analogues exhibited a constant difference independent on the substance adsorbed, being $10 \mathrm{~kJ} / \mathrm{mol}$ with MFI and $6 \mathrm{~kJ} / \mathrm{mol}$ with FAU, respectively. This constant difference is in good agreement with results reported previously, ${ }^{1}$ where it was shown (i) that the strength of direct interaction between the alkanes and the acid sites changes only a little with the carbon number of the alkane and (ii) that the increase in the heat of adsorption with increasing chain length of the alkane adsorbed is mainly due to an increase in strength of lateral interaction with the zeolite lattice.

Although from this point of view the results exhibit an excellent agreement, the comparison with results of i.r. measurements suggests that a more complex situation prevails. It was shown previously ${ }^{1}$ by i.r. spectroscopy that the direct interaction between sorbed alkanes and the acid sites of H-MFI and H-FAU is of similar strength. Therefore, we would expect nearly the same difference between the initial heat of alkane sorption on the acidic and the neutral samples of these two structures. However, this difference is clearly higher with MFI than with FAU. This suggests that the higher (overall) heat of adsorption due to the direct alkane-

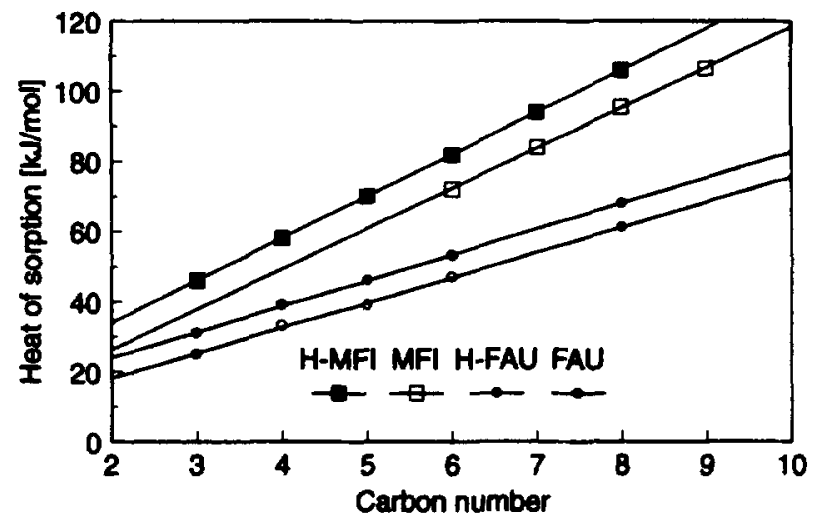

Figure 7 Heat of $n$-alkane sorption on acidic and neutral MFI and FAU. acid site interaction is partly compensated by a weaker interaction of the zeolite with the rest of the molecule. This is speculated to be related to the presence of aluminum in the framework of the acidic molecular sieve, which increases the polarity of the lattice and, hence, reduces the interaction with the apolar alkanes. Note that this effect is more pronounced for H-FAU than for $\mathrm{H}-\mathrm{MFI}$, as it has a higher concentration of $\mathrm{Al}^{3+}$ in the framework.

The compensation effect between enthalpy and entropy of sorption reported for $n$-alkane sorption on acidic zeolites ${ }^{1}$ is also scen for the purcly siliceous samples (see Figure 8). The same enthalpy of adsorption results in higher entropy of adsorption for MFI compared with that for FAU. This confirms again that the interactions of the alkanes with the MFI lattice is more pronounced than the interaction with the lattice of FAU.

\section{CONCLUSIONS}

Sorption of alkanes in molecular sieves seems to be governed by a multitude of influences. In addition to a general increase of the strength of interaction with the size of the $n$-alkane and a decrease in the pore size of the molecular sieve, ordering, intermolecular interactions, and interaction with the acid sites are important. The role of ordering on the shape of the adsorption isotherm and the maximum uptake is well illustrated with the sorption of $n$-hexane and $n$-heptane in MFI. Molecules sorbed in the zig-zag channels of MFI hinder the sorption in the straight channels by partially blocking the intersections. To reach pore filling, these molecules have to be confined to their position. As higher partial pressures are necessary to overcome this entropically less favorable situation loss, a kink or even a plateau is observed in the isotherms. At elevated temperatures (i.e., $n$-heptane sorption at $373 \mathrm{~K}$ ) the thermal motions of the molecules are too high to realize such confinement.

The role of intermolecular interactions for stabilizing the sorbate is best illustrated by sorption on FAU and EMT. These interactions lead to an increase in the differential heat of adsorption with the loading for a

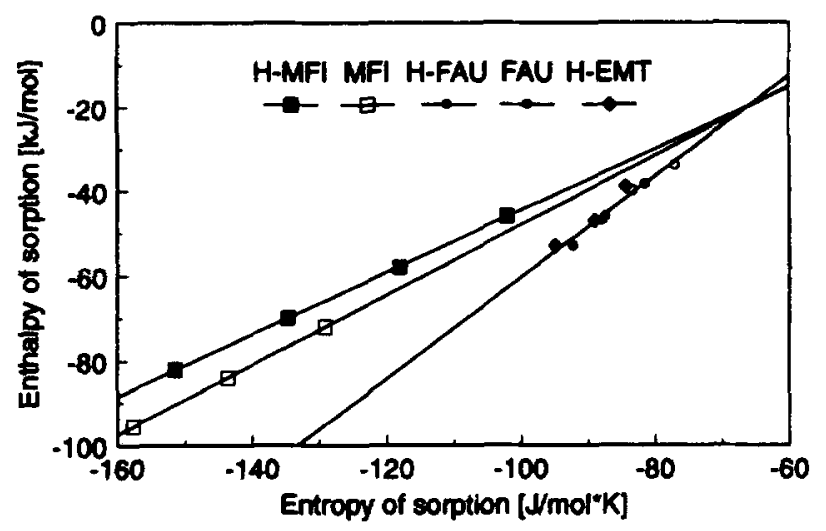

Figure 8 Interdependence of enthalpy and entropy of sorption on acidic and neutral MFI and FAU and on H-EMT, respectively. 
maximum of $80 \%$ of the heat of condensation. By adsorbing molecules, energetically favored sorption sites are created, i.e., sites with neighboring preadsorbed molecules. This leads to a different shape of the isotherm, deviating from a Langmuir model.

The role of the interaction with the acid sites is illustrated by a comparison of acidic and nonacidic molecular sieves. The contribution of the acid sites to the sorption enthalpy of alkanes is found to be $10 \mathrm{~kJ} / \mathrm{mol}$ with MFI and $6 \mathrm{~kJ} / \mathrm{mol}$ with FAU. The lower value found with FAU is attributed to a partial compensation of the stronger alkane acid site interaction by a weaker interaction of the zeolite with the rest of the molecule, as the presence of $\mathrm{Al}^{3+}$ decreases the polarizability of the zeolite lattice.

As with acidic zeolites, the enthalpy and the entropy of adsorption on siliceous samples exhibit a linear relationship. The higher entropy loss observed on MFI suggests more pronounced interactions with the lattice of MFI and tighter bound surface complexes than with FAU.

\section{ACKNOWLEDGMENTS}

Financial support of this work by the Shell Research and Technology Centre, Amsterdam, is gratefully acknowledged. We want to thank Dr. H. Kessler for pro- viding the EMT sample and Prof. J.H.C. van Hooff for providing the silicalite sample.

\section{REFERENCES}

1 Eder, F., Stockenhuber, M. and Lercher, J.A. J. Phys. Chem. submitted for publication

2 Thamm, H. Zeolites 1987, 7, 341

3 Thamm, H., Stach, H. and Fiebig, W. Zeolites 1983, 3, 95

4 Stach, H., Lohse, U., Thamm, H. and Schirmer, W. Zeolites $1986,6,74$

5 Abdul-Rehman, H.B., Hasanain, M.A. and Loughlin, K.F. Ind. Eng. Chem. Res. 1990, 29, 1525

6 Doelle, H.-J., Heering, J., Riekert, L. and Marosi, L. J. Catal. $1981,71,27$

7 Richard, R.E., and Rees, L.V.C. Langmuir 1987, 3, 335

8 Titiloye, J.O., Parker, S.C., Stone, F.S. and Catlow, C.R.A. J. Phys. Chem. 1991, 95, 4038

9 June, R.L., Bell, A.T. and Theodorou, D.N. J. Phys. Chem. 1992, 96, 1051

10 Smit, B. and Siepmann, J.I. J. Phys. Chem. 1994, 98, 8443

11 Smit, B. and Maesen, T.L. Nature 1995, 374, 42

12 Maginn, E.J. Bell, A.T. and Theodorou, D.N. J. Phys. Chem. 1995, 99, 2057

13 Stach, H., Fiedler, K. and Jänchen, J. Pure Appl. Chem. 1993, 65, 2193

14 Jänchen, J., Stach, H., Grobet, P.J., Martens, J.A. and Jacobs, P.A. Zeolites 1992, 12, 9

15 van Well, W.J.M., Wolthuizen, J.P., Smit, B., van Hooff, J.H.C. and van Santen, R.A. Angew. Chem. Int. Ed. Engl. 1995, 34, 2543 